\title{
SOBRE UN SUPUESTO DESCUIDO DEL CAPÍTULO LI DEL QUIJOTE DE 1605
}

En el capítulo LI, ya acabando el Quijote de 1605, ofrece Cervantes su último relato intercalado: la historia de la bella Leandra y del soldado "valiente" que supo conquistar la voluntad femenina. El capítulo contiene, en el texto princeps, dos problemas de relieve bibliográfico: el significado de "Gante y Luna" y la vacilación entre Vicente de la Rosa y Vicente de la Roca. El precioso estudio de la profesora Carrasco Urgoiti ' pone fin, pensamos, a las conjeturas de "error cervantino o de imprenta" en lo que se refiere a "Gante y Luna". Resta, con todo, el conflicto entre "Rosa" y "Roca", pues las ediciones modernas, en las distintas formas que optan por presentar el capítulo, siguen dando a entender, como única opción, que ello representa un descuido de Cervantes o de su editor: a) retienen, por respeto al texto princeps, los dos apellidos, indicando la discrepancia ${ }^{2}$; b) optan, siguiendo la edición de 1608 , en cuya impresión no parece haber participado Cervantes ${ }^{3}$, por "Roca" 4; o c) dejándose llevar por el más veces usado, optan por "Rosa"s.

Descartando de momento, por cómoda y estéril, la noción de descuido, sea de quien fuere, adquiere cuerpo la posibilidad, cuando

\footnotetext{
' M. S. Carrasco Urgoiti, " "Más singulares desafíos, según él decía, que Gante y Luna...": nota a una alusión del Quijoten, en Estudios sobre literatura y arte dedicados al profesor Emilio Orozco Díaz, I. Granada, Univ. de Granada, 1979.

2 Véase, por ejemplo, la edición de J. B. Avalle-Arce: M. DE CERvantes, Don Quijote de La Mancha. Madrid, Editorial Alhambra, 1979.

3 R. M. Flores, The Compositors of the First and Second Madrid Editions of Don Quijote, Part I. London, The Modern Humanities Research Association, 1975.

4 Véanse, por ejemplo, las siguientes ediciones: J. Alcina Franch, Don Quijote de La Mancha. Zaragoza, Cometa, S. A., 1977; L. A. Murillo, Don Quijote de La Mancha. Madrid, Castalia, 1978, F. Rodríguez Marin, Don Quijote de la Mancha. Madrid, Ediciones Atlas, 1947.

5 Véanse, por ejemplo, las siguientes ediciones: J. J. Allen, Don Quijote de La Mancha. Madrid, Ediciones Cátedra, S. A., 1977; M. de Riquer, Don Quijote de La Mancha. Barcelona, Editorial Planeta, 1975.
} 
menos hipotética, de que se trata de una polionomasia consciente y artistica. Sugiere esta posibilidad el hecho notorio de que Cervantes utiliza la ambivalencia apelativa constantemente a través de la novela "; pero hay, además, otros indicios que la refuerzan. Es de notar que Cervantes, en el caso que estudiamos, llama la atención del lector muy especialmente sobre los nombres de los personajes del cuento intercalado:

Llámase mi competidor Anselmo, y yo Eugenio, porque vayáis con noticia de los nombres de las personas que en esta tragedia se contienen.

Esto, que pudiera pasar desapercibido y que nada prueba en sí, no deja de poder interpretarse como preparación adelantada del escritor (o del personaje que narra) para su próxima y estudiada polionomasia. Y es un hecho, asimismo, que existe una sutil pero inconfundible relación metafórica entre los distintos apellidos que se le aplican al protagonista del cuento y las distintas fases del mismo que se presentan. Mientras que la narración de Eugenio retrata al soldado, todo colores y plumas, todo palabrería y jactancias, se le llama (dos veces) Vicente de la Rosa. Después, cuando roba y abandona a la enamorada Leandra (dejándole, sorprendentemente, la virtud), se le llama Vicente de la Roca. La correspondencia es, nos parece, inescapable: Rosa $=$ colorido vestuario y floreo verbal; Roca = dureza, al abandonar, e insensitividad pétrea, al no dignarse gozar, a la bella Leandra.

Veamos lo que supondría aceptar, siquiera de momento, esta conjetura. Nada sorprende ya al lector (hacia finales de la Primera Parte) la polionomasia cervantina. La ha habido, escandalosamente extrema ?, respecto al nombre verdadero del protagonista y, descriptiva e incongruente ${ }^{8}$, respecto al nombre de su cómico escudero. Mas la diferencia que ofrece el caso de Vicente de la Rosa/Roca, si lo fuese, es que se trata de una polionomasia que lleva a cabo un narrador ficticio, el cabrero Eugenio. Para su última ambivalencia apelativa de la Primera Parte, Cervantes habría llevado esa desdibujante técnica barroca hasta el extremo que supone su delegado empleo por uno de los personajes ${ }^{9}$.

Es por demás curioso, asimismo, el tipo de nombre que empieza Cervantes por darle a su soldado. Lo es porque apellidos con la partícula de, pese a su larga historia de designación hidalga, adquieren, después del advenimiento de la "novela picaresca" (cuando escribe Cervantes su Primera Parte hacen eco los nombres de

- L. SPITZER, "Linguistic Perspectivism in Don Quijote», en Linguistics and Literary History: Essays in Stylistics. Princeton, Princeton Univ. Press, 1948.

? R. R. MACCuRdy y A. Rodríguez, «Algo más sobre los apellidos verdaderos de don Quijoten, Romanische Forschungen 90, 1978, pp. 448-57.

"D. Fernández-Morera, "Cervantes and the Aesthetics of Reception», Comparative Literature Studies, 18, 1981, p. 406.

ฯ Caso parecido, de la delegación de una polionomasia a un personaje, sería la del vecino de don Quijote en I, v. 
lazarillo de Tormes y Guzmán de Alfarache), una equívoca resonancia picaresca. En el caso concreto del Quijote, el estudio de Reyre ${ }^{10}$ sugiere que cuando Cervantes emplea semejantes apellidos sin ir precedidos de "don" u otro indicio de nobleza, se trata, casi invariablemente, de un pícaro o, cuando menos, de un tipo apicarado.

En efecto, si la nominación de Vicente de la Rosa/Roca sugiere que Cervantes lo percibió creativamente en términos picarescos, y si, además, su conducta en el cuento de Eugenio es del todo en todo una conducta picaresca (lo cual daría mayor sentido al robo de las joyas y no de "la joya" de la enamorada Leandra), no hay razón para no clasificarle, soldado engañoso, mentiroso y ladrón, como pícaro ". En este sentido, basta recordar el famoso soneto cervantino, que podría pasar por caracterización anticipada del soldado del Quijote:

\author{
Un valentón de espátula y gregüesco \\ que a la muerte mil vidas sacrifica, \\ cansado del oficio de la pica \\ mas no del ejercicio picaresco, \\ retorciendo el mostacho soldadesco, \\ por ver que ya su bolsa le replica, \\ a un corrillo llegó de gente rica, \\ y en nombre de Dios pidió refresco. \\ Den, voacedes, por Dios, a mi pobreza, \\ les dice: Donde no, por ocho santos \\ que haré lo que hacer suelo sin tardanza. \\ Mas uno que a sacar la espada empieza, \\ con quien habla, le dijo: ¿El tiracantos, \\ si limosna no alcanza \\ qué es lo que suele hacer en tal querella? \\ Respondió el bravonel: Irme sin ella.
}

Ahora bien, si Cervantes acudió a modelo picaresco para crear al soldado embaucador de Leandra, nada extraña (aunque proceda de Eugenio, cabrero y narrador) que, como en el caso del más famoso pícaro del Quijote, Ginés de Pasamonte, se le presente -reconocimiento del proteísmo esencial de lo picaresco ${ }^{12}-$ con ambivalencia apelativa.

\title{
ALFRED RODRÍGUEZ \\ The University of New Mexico
}

10 D. REYre, Dictionnaire des Noms des personnages du Don Quichotte de Cervantes. Paris, Editions Hispaniques, 1980.

". Una explicación etimológica de "pícarow, habría que recordar, es de "piquero", es decir, "soldadow. Véase H. Sieber, The Picaresque. London, Methuen \& Co., Ltd., 1977, p. 6.

12 Para la asociación del proteísmo con el pícaro, particularmente en Cervantes, véanse A. K. ForCIONE, Cervantes and the Mystery of Lawlessness. Princeton, Princeton Univ. Press, 1984, p. 26; y H. H. REED, "Theatricality in the Picaresque of Cervantesw, Cervantes, 7, 1987, pp. 80-81. 